\title{
EFFECT OF DGS ON CHARACTERISTICS OF RECTANGULAR MICROSTRIP PATCH ANTENNA
}

\author{
Amar B. Kachare ${ }^{1}$, Mahesh.S.Mathpati ${ }^{2}$ \\ ${ }^{I}$ M.E Student, Electronics and Telecommunication Engineering Department, SVERI's College of Engineering, \\ Pandharpur, Maharashtra, India \\ ${ }^{2}$ Assistant Professor, Electronics and Telecommunication Engineering Department, SVERI`s College of Engineering, \\ Pandharpur, Maharashtra, India
}

\begin{abstract}
The need of multiband, larger gain and low profile antennas to support multiple wireless applications led to the design of Microstrip antennas. Microstrip antennas due to their small profile design take less area. Further they can be modified by two techniques that are introducing defect in ground plane and adding layers to the conducting surface in order to improve its gain, VSWR, bandwidth, return loss and directivity. This paper presents the changes in the above characteristics of micostrip patch antenna with addition of defect and different shape of defects. The proposed antenna is simulated on Duroid substrate with dielectric constant of 2.2 and fed with 50 ohms microstrip line using HFSS software. By introducing the defect in the ground plane and changing its shape the corresponding changes in the characteristics have been noted for $2.4 \mathrm{GHz}$ of resonant frequency.
\end{abstract}

Keywords-Microstrip patch antenna; Defected ground structure

\section{INTRODUCTION}

DGS which stands for Defected Ground Structure is a newly introduced revolutionary technique in the field of Microstrip antenna to enhance the performance of antenna especially the bandwidth. By introducing the defect in ground plane means changing or modifying the shape of ground plane, which is in normal case is a planar shape.

Basically, DGS is periodic or non-periodic cascaded defect in ground of a planar transmission line achieved by etching process, causes to disturb the shield current distribution in the ground plane because of the defect introduced in the ground plane. The disturbance in shield current distribution eventually results in change of the characteristics of transmission line such as capacitance and inductance. The effective resultant of this is improvement in the capacitance and inductance hence we get as a result in improved bandwidth for the antenna. This paper will show the effective comparison between antenna characteristics for no DGS shape, Simple DGS shape and special DGS Shape of ground plane.

\section{DESIGN CALCULATIONS FOR}

\section{MICROSTRIP PATCH}

\subsection{Design Requirements}

The patch antenna has been designed for achieving following requirements.

- Resonant frequency $\left(\mathrm{f}_{\mathrm{r}}\right)=2.45 \mathrm{Ghz}$

- Dielecrtric constant $(\varepsilon r)=4.4$

- $\quad$ Bandwidth $(\mathrm{Bw})>120 \mathrm{Mhz}$

- Return loss $>-10 \mathrm{~dB}$

- $1<\mathrm{VSWR}>2$

\subsection{Antenna Geometry}

- Width of patch

$$
W=\frac{\mathrm{C}}{2 \mathrm{fr} \sqrt{\frac{\varepsilon r+1}{2}}}
$$

$\mathrm{W}=43.29 \mathrm{~mm}$

- $\quad$ Effective dielectric constant

$$
\begin{aligned}
& \text { ereff }=\frac{(\varepsilon r+1)}{2}+\frac{(\varepsilon r-1)}{2}\left(1+12 \frac{h}{w}\right)^{\frac{-1}{2}} \\
& \text { ereff }=2.8388
\end{aligned}
$$

Then calculate the effective length.

- Effective length

$$
\begin{aligned}
& \text { Leff }=\frac{C}{2 * F r * \sqrt{(\text { greff })}} \\
& \text { Leff }=36.34 \mathrm{~mm}
\end{aligned}
$$

- $\quad$ Delta length

$$
\begin{aligned}
& \Delta L=0.412 h \frac{(\text { Ereff }+0.3)\left(\frac{w}{h}+0.264\right)}{(\text { greff }-0.258)\left(\frac{w}{h}+0.8\right)} \\
& \Delta L=747.7 \mu \mathrm{m}
\end{aligned}
$$

- $\quad$ Actual length

With the effective length and delta length now calculate the actual length patch: 
$\mathrm{L}=\operatorname{Leff}-(2 * \Delta \mathrm{L})$

\section{$\mathrm{L}=34.84 \mathrm{~mm}$}

- $\quad$ Ground plane

The width and length ground plane can be calculated by the following equations:

$$
\begin{aligned}
& \mathrm{Wg}=6 * \mathrm{~h}+\mathrm{W}=52.41 \mathrm{~mm} \\
& \mathrm{Lg}=6 * \mathrm{~h}+\mathrm{L}=43.96 \mathrm{~mm}
\end{aligned}
$$

\section{SIMULATION SOFTWARE}

For the simulation purpose application software from Ansoft called HFSS is used. It is one of the most precise antenna simulation software on the market. Modeling of the patch antenna using the calculated geometrical dimension is done prior.

HFSS offers a dynamic selection of geometrical shapes which builds really helpful tool while drawing 3-D models. The three different ground planes are designed by using Boolean and subtraction operation available in the HFSS.

\section{DESIGN MODELS}

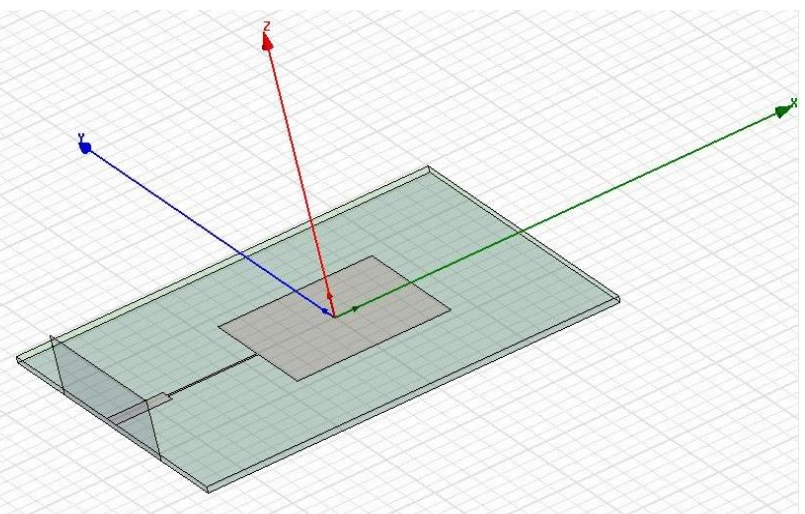

Fig.1 Design Model1: Patch antenna without DGS

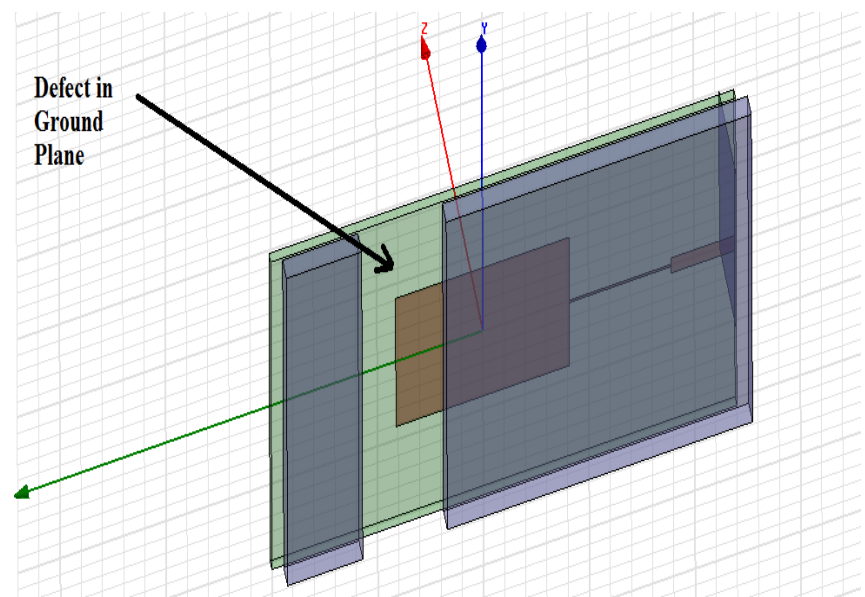

Fig.2 Design Model2: Patch antenna with simple DGS

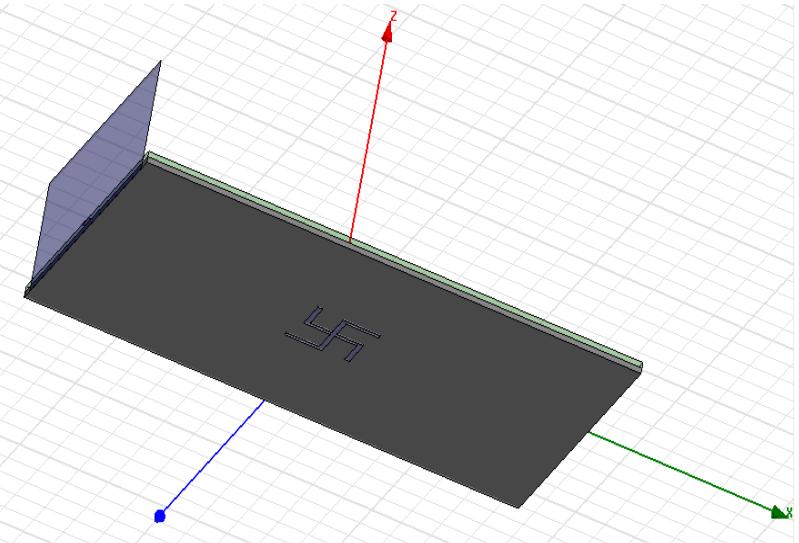

Fig.3 Design Model2: Patch antenna with special shaped DGS

Model number one in Fig.1 shows microstrip patch antenna without DGS meaning the conducting ground surface is plane throughout. The shield current distribustion in this case is totally dependent on the patch dimensions and substrate material characteristics.

Model number two shown by Fig.2 is same patch antenna but with modified ground plane. Instead of keeping plane ground surface the part of conducting ground is removed. This makes a simple defect in the ground plane. In this case the shield current distribution will be different than that of previous case.

Model number three in Fig.3 shows the swastik shaped defected structure for the same patch geometry.

\section{RESULTS OF SIMULATION}

\subsection{Bandwidth and Return loss}

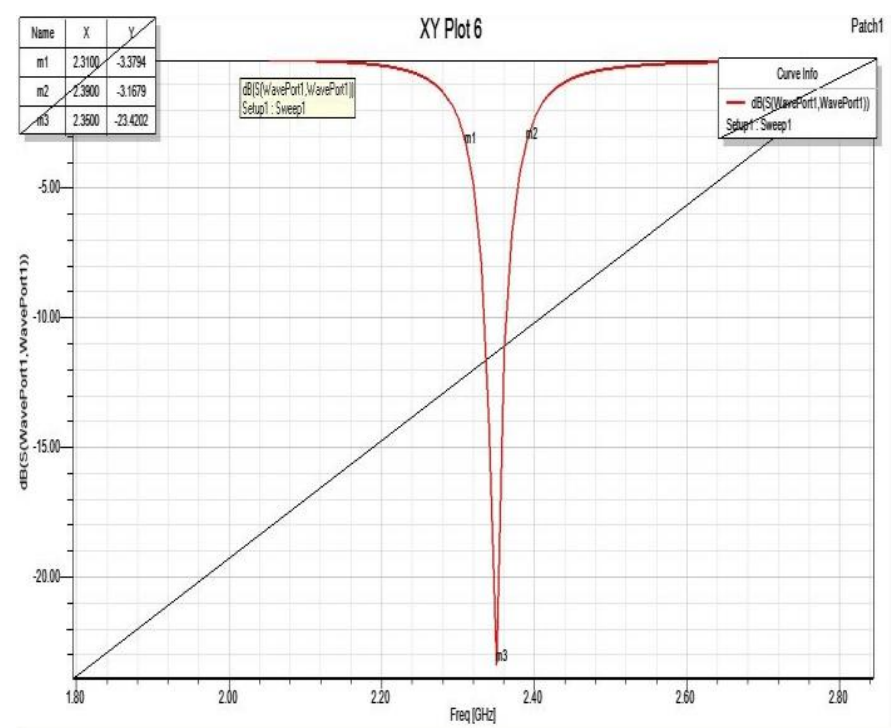

Fig.4 Return loss and bandwidth for Model1 (no DGS) 


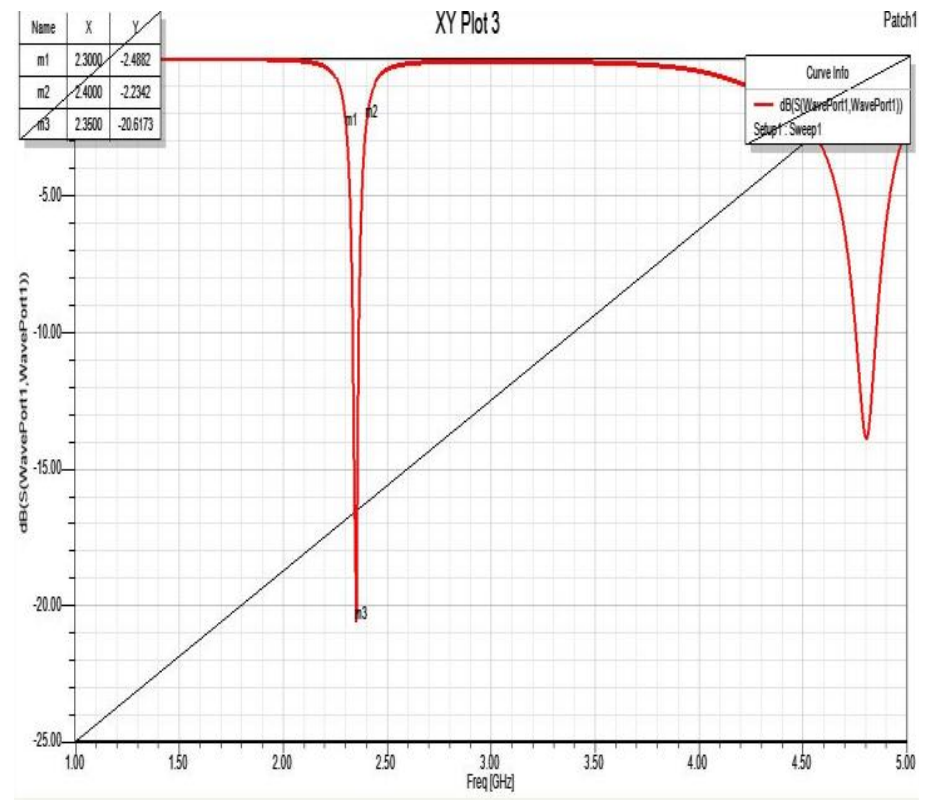

Fig.5 Return loss and bandwidth for Model2 (Simple DGS)

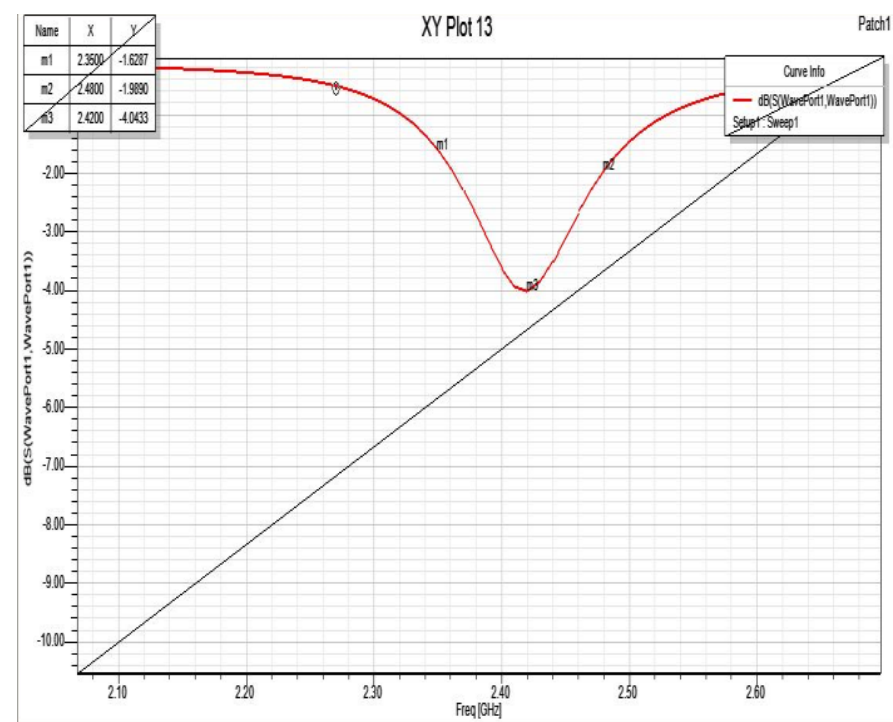

Fig.6 Return loss and bandwidth for Model3 (Special DGS)

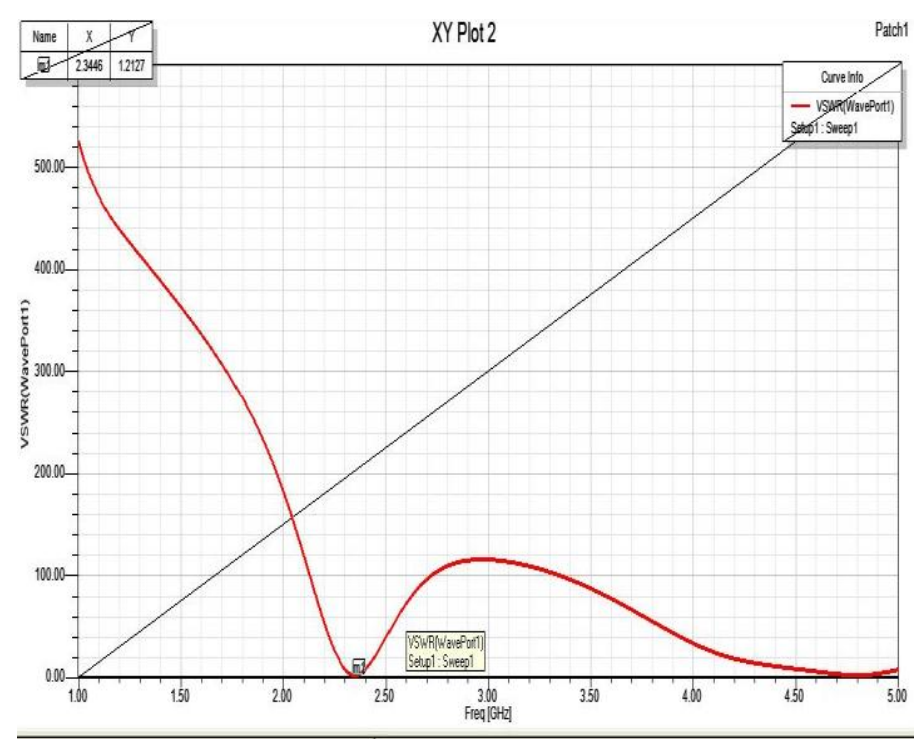

Fig.7 VSWR for Model1 (No DGS)

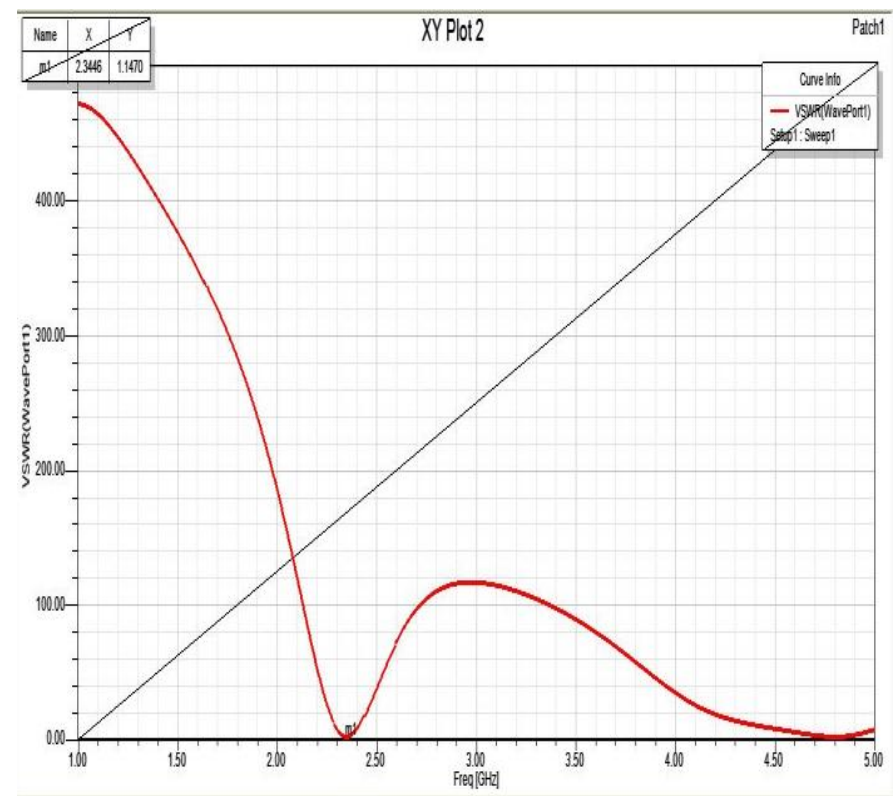

Fig.8 VSWR for Model2 (Simple DGS)

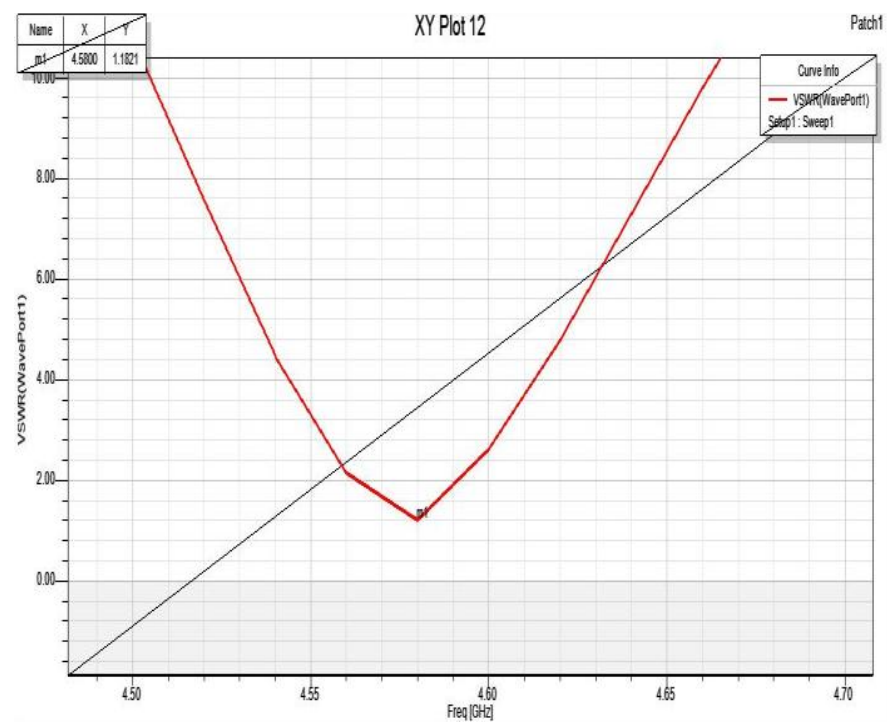

Fig.9 VSWR for Model3 (Special DGS)

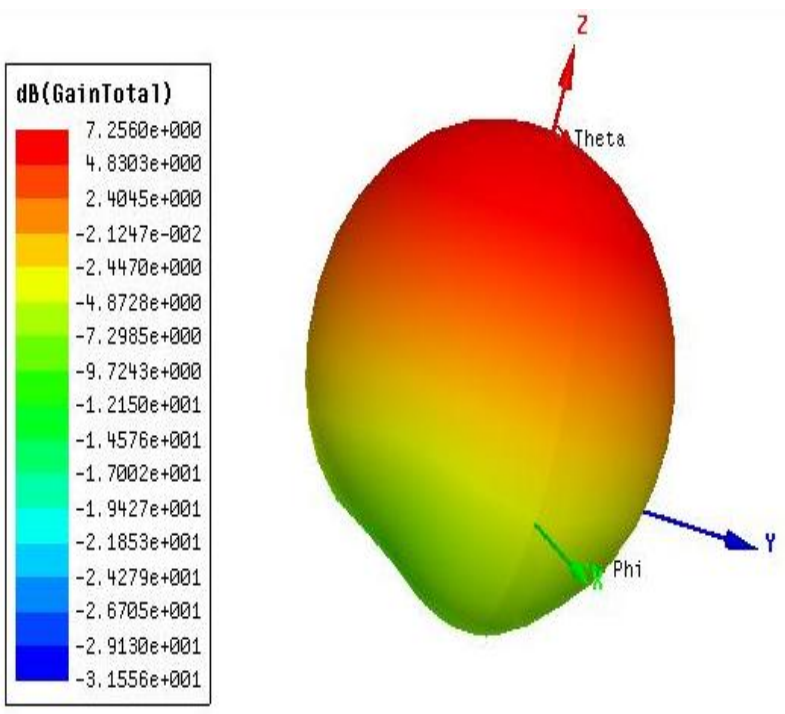

Fig.10 Total Gain for Model1 (No DGS) 


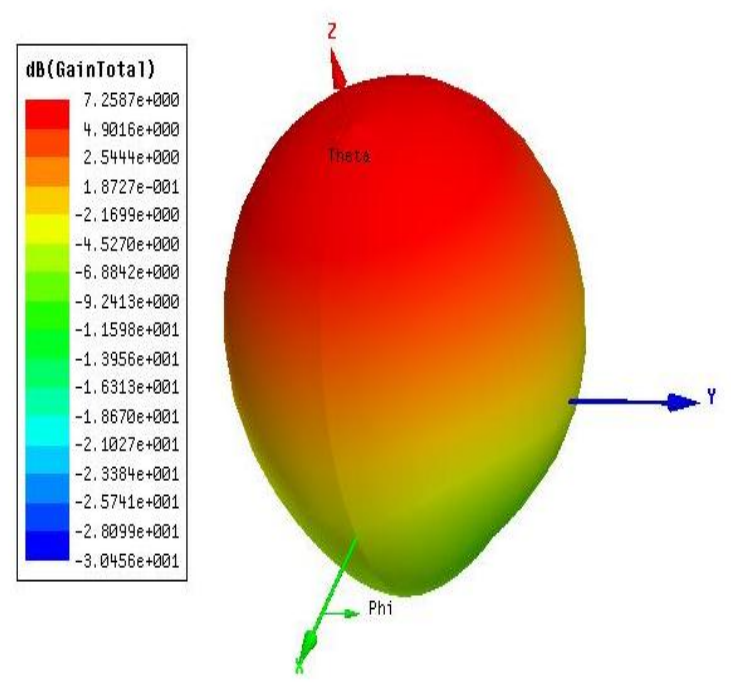

Fig.11 VSWR for Model2 (Simple DGS)
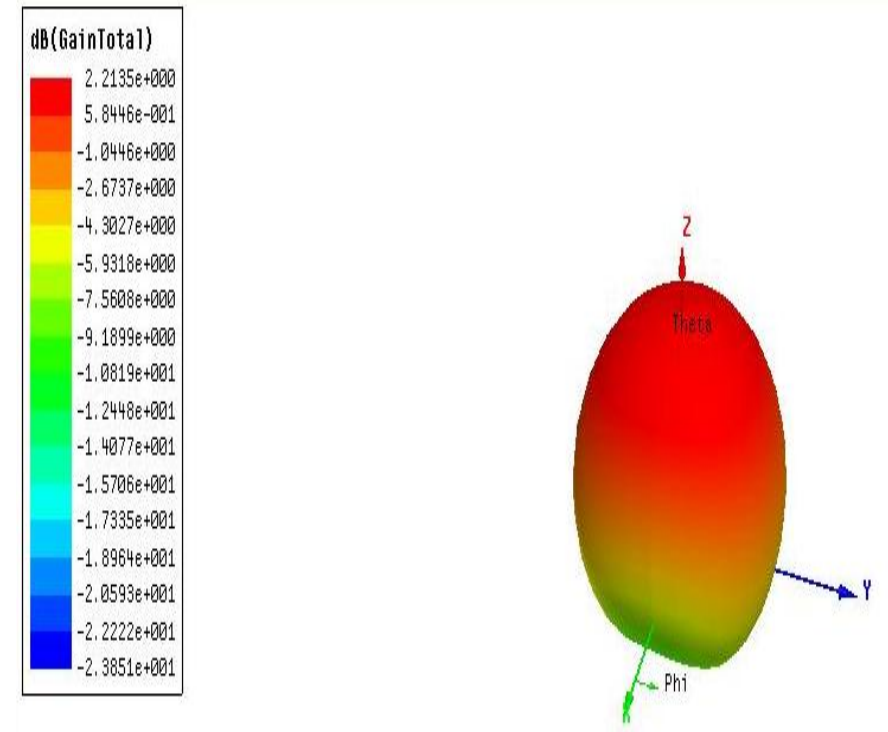

Fig.12 VSWR for Model3 (Special DGS)

\section{CONCLUSION AND RESULT ANALYSIS}

It would have been a big advantage to know the Ansoft HFSS simulation software beforehand as a lot of measurements could have been applied. Microstrip antennas and their theory get much more complex as you want to create more efficiency and wider bandwidth.

With DGS the parameters of simple rectangular microstrip patch antenna such as Bandwidth, return loss and VSWR has been improved as compared with that of plane ground structure and also there is small amount of reduction in gain and directivity. There is $20 \%$ of improvement observed in Bandwidth in a comparison of No DGS and simple DGS structure. Same is about 63\% is observed in Swastik shape DGS. Thus it Can be concluded that with a proper DGS structure the BW can be improved with penalty of small amount of reduction in gain.
All the three designs have shown the VSWR ratio within the standard range of 1 to 2 . A simple DGS has shown the nearest value to 1 compared to the other two. Return loss criteria is most satisfying with the swastik shaped DGS. A Simple DGS has shows most amongst all. A slight reduction in gain is seen with the defected ground but it can be improved by designing a proper shape of DGS.

Table 1

\begin{tabular}{|l|l|l|l|l|}
\hline \multirow{2}{*}{$\begin{array}{l}\text { Desig } \\
\text { n type }\end{array}$} & \multicolumn{4}{|l|}{ Result Analysis } \\
\cline { 2 - 5 } & $\begin{array}{l}\text { Bandwidth( } \\
\text { Mhz })\end{array}$ & $\begin{array}{l}\text { Return } \\
\text { loss }(\boldsymbol{d B})\end{array}$ & VSWR & $\begin{array}{l}\text { Gain } \\
(\boldsymbol{d B})\end{array}$ \\
\hline $\begin{array}{l}\text { No } \\
\text { DGS }\end{array}$ & 80 & -23.4202 & 1.7121 & $\mathbf{7 . 2 5 6 0}$ \\
\hline $\begin{array}{l}\text { Simple } \\
\text { DGS }\end{array}$ & 100 & -20.6171 & 1.1470 & $\mathbf{7 . 2 5 8 7}$ \\
\hline $\begin{array}{l}\text { Specia } \\
\text { l DGS }\end{array}$ & 130 & -14.0344 & 1.1821 & $\mathbf{5 . 8 4 4 6}$ \\
\hline
\end{tabular}

\section{REFERENCES}

[1] Ian T. McMichael, Member, IEEE, Eric C. Nallon, Vincent P. Schnee, Waymond R.Scott,Jr.,Fellow, IEEE, and Mark S. Mirotznik, Senior Member, IEEE "EBG Antenna for GPR With a Metal Detector for Landmine Detection" published in "IEEE Geosciencean Remote sensing letters, vol. 10, no. 6, november 2013"

[2] Ian T. McMichael, Member, IEEE, Eric C. Nallon, Vincent P. Schnee, Waymond R.Scott,Jr.,Fellow, IEEE, and Mark S. Mirotznik, Senior Member, IEEE "EBG Antenna for GPR With a Metal Detector for Landmine Detection" published in "IEEE Geosciencean Remote sensing letters, vol. 10 , no. 6, november 2013"

[3] Progress In Electromagnetic Research B, Vol. 7, 173-189, 2008 “AN OVERVIEW ON DEFECTED GROUNDSTRUCTURE” byL. H. Weng, Y. C. Guo, X. W. Shi. Progress in electromagnetics research c, vol. 7, 13-24, 2012 "Effects of soil physical

[4] YABLONOVITCH, E. Photonic crystals. J. Modern Opt., 1994, vol. 41, no. 2, p. 173,194.

[5] "Microstrip patch antenna with defected ground structure \& defected microstrip Structure" Published in "Recent Advances in Microwave Theory andapplications,2008."MICROWAVE

2008.International Conference.

[6] "Microstrip patch antenna with defected ground structure \& defected microstrip Structure" Published in "Recent Advances in Microwave Theory andapplications,2008.'MICROWAVE

2008.International Conference.

[7] "Efficiency enhancement of microstrip patch antenna with defected groundstructure" Published in "Recent Advances in Microwave Theory andapplications,2008." MICROWAVE 2008.International Conference. 
[8] Mutual Coupling Reduction of Microstrip Antennas using Defected Ground Structure Published in Communication systems, 2006. ICCS 2006.10th IEEE Singapore International Conference.

[9] I. Chang, B. Lee, "Design of Defected Ground Structures for Harmonic

[10] Control of Active Microstrip Antennas," IEEE APInternationalSymposium, Vol. 2, 852.

[11] Structure for microstrip lines. IEEE MicrowaveGuided Wave Lett.,1998, vol. 8, no. 2,69 $-71$. 